\title{
Evidence-Based Management of Colorectal Trauma
}

\author{
Eric K. Johnson • Scott R. Steele
}

Received: 23 May 2013 / Accepted: 17 June 2013 / Published online: 4 July 2013

(C) 2013 The Society for Surgery of the Alimentary Tract (outside the USA)

Keywords Colon Trauma $\cdot$ Rectal trauma $\cdot$ Colon injury Rectal injury $\cdot$ Colorectal trauma $\cdot$ Traumatic injury of the colon and rectum $\cdot$ Abdominal trauma

\section{Introduction}

Despite years of debate, optimal management of the individual sustaining trauma to the colon and rectum continues to evolve. Current US military and worldwide combat operations have brought added emphasis to the controversies surrounding the proper management of these patients in both the military and civilian sectors. There has been a steady progression over time from nonoperative strategies to primary repair, and mandatory fecal diversion or injury exteriorization to the current recommendations of primary repair/resection and reanastomosis. Furthermore, while proximal fecal diversion remains an important option in the treatment of extraperitoneal rectal injuries, the

The opinions and assertions contained herein are the private views of the authors and are not to be construed as official or as reflecting the views of the Department of Defense. Use of commercial products in this project does not imply endorsement by the US Government.

Our team includes military service members and employees of the US Government. This work was prepared as part of our official duties. Title 17 U.S.C. 105 provides that "Copyright protection under this title is not available for any work of the United States Government." Title 17 U.S.C. 101 defines a US Government work as a work prepared by a military service member or employee of the US Government as part of that person's official duties.

This work was presented as part of the Evidence-Based Management of Colorectal Diseases maintenance of certification course at the 2013

SSAT/DDW meeting in Orlando, FL, USA.

E. K. Johnson · S. R. Steele

Department of Surgery/Colorectal Surgery, Madigan Army

Medical Center, Joint Base Lewis-McChord, Tacoma,

WA 98431, USA

E. K. Johnson $(\square)$

2506 6th St NW, Gig Harbor, WA 98335, USA

e-mail: doktrj@gmail.com use of traditional adjuncts has been challenged. Finally, increased utilization of damage control techniques has added not only another option to a surgeon's disposal, but also to the controversy surrounding management as well. This article will evaluate the current evidence regarding colorectal trauma and provide recommendations for the care of these patients.

\section{Etiology and Patterns of Injury}

\section{Incidence}

While it is difficult to precisely determine the incidence of both colon and rectal injuries, primarily due to the retrospective cohort nature of most published series, we can make certain inferences from the literature. In general, reports of individuals injured in combat reveal a higher incidence of colonic injuries at 5-10\%. ${ }^{1-3}$ We can also note that the mechanism of injury varies based on environment. A recent study of colorectal injuries encountered in Afghanistan and Iraq reveals that $71 \%$ of injuries occurred secondary to penetrating trauma, $23 \%$ were secondary to blast, and $5 \%$ occurred during blunt trauma. ${ }^{4}$ Civilian series have found lower overall incidences, between 1 and $3 \%$, with fewer injuries related to high-energy and blast mechanisms. Colorectal injury is even less common when the mechanism is blunt trauma, with reported rates as low as $0.1-0.5 \% .{ }^{5-7}$ Mechanism of injury also varies based on geographic location and culture, with rates of blunt colorectal trauma in urban South Africa (where penetrating injuries predominate) reported as low as $0.02 \%{ }^{8}$ Because the "cost" of a missed injury is so high, it is imperative that surgeons maintain a high index of suspicion for these injuries. Blunt hollow visceral injuries typically occur in the setting of high-energy transfer, and are often accompanied by head, chest, solid organ, spine, and orthopedic injuries. ${ }^{9}$ While "high-energy" wounds are more commonly associated with military environments, this may occur in the civilian sector as well. This has never been more apparent than with 
the current potential of terrorist activity as evidenced by physicians involved in treating those patients following 9/11, Oklahoma City, and the Boston Marathon attacks.

\section{Presentation}

An individual who sustains traumatic injury to the colon or rectum may present with physical signs of peritonitis - much like an individual with a nontraumatic hollow visceral perforation. This will depend on several factors: time from injury, injury severity, mental status/hemodynamic status, and associated injuries. Many of these patients are not able to communicate with the surgeon, nor can they be examined effectively. Given these barriers, one must rely on basic findings and associations with injury mechanism to select patients at risk in order to identify those requiring additional investigation for these specific injuries.

\section{Diagnosis}

Patient evaluation begins with standard Advanced Trauma Life Support primary and secondary surveys, along with concomitant resuscitation. All patients should undergo an abdominal examination to evaluate for sites of penetrating wounds or peritonitis mandating urgent exploration. In addition, the flanks and perineum should be evaluated to look for subtle signs of entry that may lead to retro- or extraperitoneal injuries that may present in a delayed fashion. Digital rectal examination (DRE) should be performed with a focus on sphincter tone, presence of blood, foreign objects, or bony protrusion - especially in those patients with pelvic fractures. When a rectal injury is suspected, rigid proctoscopy should also be performed to evaluate for mucosal or full-thickness injury, as well as documenting the degree and extent of damage. Although DRE and proctoscopy can identify blood in up to $80-90 \%$ of cases,${ }^{10}$ the sensitivity is only $\sim 33 \%$ for rectal injuries, ${ }^{11}$ and results in management alterations in fewer than $5 \%$ of cases. ${ }^{12,13}$ Upright chest radiograph may demonstrate free intraperitoneal air consistent with hollow viscus perforation. Ultrasound use via a focused assessment with sonography for trauma may demonstrate free fluid, and has been shown to be useful for both blunt and penetrating abdominal trauma, despite being nonspecific for colorectal injuries. ${ }^{14}$ Computed tomography (CT) scan has become the predominant radiological test of choice and is effective in diagnosing colorectal injuries in stable patients with no immediate indications for laparotomy. There is occasionally a debate with the radiologist regarding the need for contrast. In general, oral and rectal contrast is avoided initially in the acute setting; however, in select patients (such as a stable patient with a stab wound) these are oftentimes helpful. Triplecontrast helical CT has been shown to demonstrate up to a $100 \%$ sensitivity, $96 \%$ specificity, $100 \%$ negative predictive value, and $97 \%$ accuracy in patients evaluated for peritoneal violation, or colonic, major vascular, or urinary tract injuries following penetrating trauma. ${ }^{15,16}$ Finally, although not used as frequently, diagnostic peritoneal lavage has shown sensitivities of $84-97 \%$ for detection of intestinal injury and should remain as a tool in the armamentarium of all surgeons. ${ }^{17,18}$

\section{Management}

\section{Colonic Injuries}

Despite reports of negative laparotomy in $\sim 5-27 \%$ of abdominal gunshot wounds and up to $53 \%$ of stab wounds, penetrating abdominal injuries still tend to be managed with mandatory exploration, especially in the combat setting. ${ }^{19}$ The complications from nontherapeutic laparotomy must be weighed against the morbidity of missed injuries, and may be the driving influence behind this management strategy. In general, options for management of colon injuries include primary repair, resection and primary anastomosis (both with or without proximal diversion), and resection and fecal diversion.

\section{Primary Repair/Resection with Anastomosis Versus Diversion}

Although initially published in the early $1950 \mathrm{~s},{ }^{20}$ a publication in 1979 seemed to begin a paradigm shift in the management of penetrating colon injuries. Despite a large number of individuals failing to meet inclusion criteria, they found equivalent rates of infection ( 48 vs. $57 \%, P>0.05$ ) and mortality ( 1.5 vs. $1.4 \%, P>0.05)$ in a cohort of 139 patients that were randomized to primary repair versus colostomy. ${ }^{21}$ Many criticized this study for eliminating the sickest patients from randomization and felt this was the reason for the findings. Since this publication, the trauma literature has demonstrated successful primary repair in as many as $73-85 \%$ of civilian injuries ${ }^{22-24}$ and $11-72 \%$ of military injuries, ${ }^{1-3,25}$ regardless of the underlying conditions. Of note, most of these studies were retrospective in nature and were subject to selection bias. It took over a decade for another randomized-controlled trial to be published when, in 1991, 56 patients with penetrating colon injuries were randomized to either primary repair or diversion. ${ }^{26}$ Management of the colonic injury in this study was independent of the number of associated injuries, transfusion requirement, degree of fecal contamination, or hemodynamic stability on presentation. Septic complications were similar between the two groups (primary $(21.4 \%)$ vs. diversion $(17.9 \%)$ ), and no anastomotic leakage was seen in the primary repair cohort. Other authors in this period demonstrated that primary repair was safe and avoided the additional 
morbidity associated with stoma construction and eventual closure. ${ }^{27-29}$ In addition, destructive wounds and those cases with concomitant shock, excess blood loss, fecal contamination, and multiple organ injuries appeared to gain no benefit from diversion, ${ }^{30}$ though some authors still recommended stoma placement for high-risk patients and in those where technical problems occurred. ${ }^{31,32}$ Guidelines have since been published that recommend the use of fecal diversion in circumstances of destructive wounds with a penetrating abdominal trauma index (PATI) $>25$, associated comorbidity, and hemodynamic instability. ${ }^{33}$ Others suggest colostomy can be avoided when the PATI $<15$, there is minimal peritoneal contamination, and there is an absence of hypotension. ${ }^{34}$ Importantly, these recommendations were all based on class III and limited class II data.

A more recent multicenter prospective trial involving 19 trauma centers including 297 patients with destructive colon injuries requiring resection, of which two thirds were managed by primary anastomosis, ${ }^{35}$ revealed that colon-related mortality was significantly lower in the primary anastomosis group ( 0 vs. $4 \%, P=0.012$ ), with no difference in colonrelated complications ( 22 vs. $27 \%, P=0.373$ ). The authors found that although the presence of severe fecal contamination, transfusion of greater than four units of packed red cells within the first $24 \mathrm{~h}$, and single-agent antibiotic prophylaxis were all independently associated with increased complications, outcomes were not related to the method of management of the colonic injury. This was not a randomized study, as the method of colon wound management, antibiotic use, and antibiotic duration were left to the discretion of the attending surgeon.

A meta-analysis and subsequent Cochrane Review of all prospective randomized trials from 1966 to 2001 identified only five studies that met inclusion criteria. Overall, there was no difference in mortality between primary repair versus diversion, although total complications (odds ratio $[\mathrm{OR}]=0.28$; $95 \%$ confidence interval $[\mathrm{CI}], 0.18-0.42)$, total infectious complications $(\mathrm{OR}=0.41 ; 95 \% \mathrm{CI}, 0.27-0.63)$, abdominal infections including dehiscence $(\mathrm{OR}=0.59 ; 95 \% \mathrm{CI}, 0.38$ $0.94)$, abdominal infections excluding dehiscence $(\mathrm{OR}=0.52$; $95 \%$ CI, 0.31-0.86), wound complications including dehiscence $(\mathrm{OR}=0.55 ; 95 \% \mathrm{CI}, 0.34-0.89)$, and wound complications excluding dehiscence $(\mathrm{OR}=0.43 ; 95 \% \mathrm{CI}, 0.25-0.76)$ all significantly favored primary repair. ${ }^{36,37}$

This is not to say that all patients undergoing diversion are not treated properly. Despite evidence supporting primary repair, some have attempted to identify a subgroup of patients that benefit from proximal diversion. One group had previously demonstrated that preoperative or intraoperative transfusion of more than six units of packed red blood cells or those patients with severe comorbid disease developed suture line failure more often following primary anastomosis (42 vs. $3 \%$ ). ${ }^{38}$ One third of those patients sustaining a leak died. Based on this data, investigators developed a clinical pathway such that the presence of either of these two conditions would prompt an end colostomy. ${ }^{22}$ Using this algorithm, they were able to decrease their anastomotic leak and abscess rate, lower colon-related mortality, and reduce the rate of fecal diversion. A more recent 2009 review evaluating the available level I data concluded that primary repair of all colorectal injuries should be attempted, irrespective of associated risk factors. ${ }^{39}$

In summary, the largest study, though nonrandomized, suggests that certain factors play an independent role in the development of complications-irrespective of the method of colon repair. Despite the preponderance of evidence supporting primary repair, there continues to be debate. Primary repair of penetrating colon injuries is likely as safe as diversion, especially for nondestructive colon injuries. Destructive colon injuries are also likely best addressed with resection and anastomosis, although some evidence suggests colostomy should be considered in patients with significant comorbidities, hemodynamic instability, and those with multiple associated injuries. Finally, no algorithm can replace surgical judgment, especially in the setting of technical issues, and diversion is likely wise and indicated when concerns with in-continuity management arise.

\section{Rectal Injuries}

Similar to colon injuries, the management of penetrating rectal injury has shifted over time. ${ }^{40,41}$ Lavenson and Cohen's Vietnam War publication on penetrating rectal injury led to the recommendations of fecal diversion, distal rectal washout, presacral drainage, and rectal repair (when feasible). ${ }^{42}$ This essentially remained the standard until being questioned in more recent civilian literature, ${ }^{43}$ as well as recent military conflicts. ${ }^{44}$ Without question, the data on rectal trauma has been less robust and almost exclusively consists of class III data from very small single-institution studies. Reports that advocate one form of management over another are plagued with selection bias and small numbers. ${ }^{21}$ Because of the confined nature of the pelvis, rectal injuries are rarely isolated, which often provides the greatest degree of variation among patients. Traditional management with diversion, repair, distal washout, and drainage may appear to be a safe approach in these complex situations.

\section{Extraversus Intraperitoneal Location}

It is important to define the anatomic location of the rectal injury as it relates to the peritoneal reflection, though similar controversy regarding the utility and need for proximal diversion versus primary repair exists with both sites. Trauma to the intraperitoneal rectum is likely best managed as a colonic injury. Extraperitoneal rectal injuries occur below the peritoneal 
reflection within the fixed pelvis, which presents many challenges. This is an area where the rectum lacks a serosa, where exposure can be difficult, and where visceral and vascular structures are located in close proximity to one another. Unlike injuries located above the peritoneal reflection, these patients are more often (and should be) treated with fecal diversion. In a study from the late 1980 s of 100 consecutive patients with injuries to the extraperitoneal rectum, $100 \%$ were treated with colostomy, with a resultant pelvic sepsis rate of $11 \%$ and overall mortality rate of $4 \%{ }^{45}$ The authors concluded that all patients with this injury should undergo proximal fecal diversion.

It is likely the complex nature of these injuries that has resulted in more consistent methods of management across both the military and civilian sectors. Some have questioned whether management should differ between the two settings. The degree of injury likely plays a major role in determining the extent of surgery required. The literature on the use of fecal diversion with or without direct injury repair is all over the map. While some studies support diversion without direct repair, ${ }^{46}$ others support selective nonoperative management of extraperitoneal rectal injuries ${ }^{47}$ using only dietary restriction and limited intravenous antibiotics with follow-up contrast radiographs. ${ }^{48}$ Despite these findings, most series employ a variety of treatment options based on proximal diversion with the addition of primary repair, presacral or transperitoneal drainage, and/or distal washout. There remains disagreement and lack of evidence regarding which regimen, or combination, is best.

As with colon injury, specific surgical procedures should be tailored to the patient based not only on the degree of rectal injury, but also on their hemodynamic status and concomitant injuries. Injuries below the peritoneal reflection may not require any exposure at all. Since they are often isolated from the peritoneal cavity, proximal diversion may be adequate treatment. Some investigators have evaluated primary repair of extraperitoneal injuries without proximal diversion, ${ }^{49}$ while others have taken a more selective approach to the addition of proximal diversion or the omission of repair based on injury location. ${ }^{50,51}$ While the results of these studies supported the authors' management algorithms, they were based on small numbers of patients and were clearly limited by selection bias. What we can gather (though based on decidedly limited data) when proximal diversion is performed, direct repair of the rectal injury is likely unnecessary. Whether direct repair is needed in the extraperitoneal location in the absence of proximal diversion is still left to question, although evidence again suggests that it is not. The larger issue is likely the complex exposure and dissection required to manage these often difficult injuries that ultimately lead to prolonged operating room times, excess blood loss, and possibly higher morbidity. These are best avoided.
In contrast to some of the data cited above, a retrospective review of colorectal injuries from Operation Iraqi Freedom in which all patients were treated with proximal diversion concluded that this strategy should still play a prominent role in the treatment of combat casualties. ${ }^{52}$ The authors found that in this setting, injuries are more often associated with high-velocity weaponry, blast wounds, increased injury severity, and complex issues native to the combat arena. This is not to mention the potential for prolonged evacuation requirements where a colostomy may be beneficial.

\section{Use of Presacral Drains}

Presacral drain usage, either via the traditional transperineal or transabdominal routes, continues to be utilized especially for those patients with extraperitoneal rectal injuries. In fact, it has been stated that "the one adjunct about which there is almost unanimous agreement is the need for drainage of the presacral space". ${ }^{46}$ Regardless of the route of drainage, proponents cite the need for proper positioning of the drain adjacent to the injury to adequately address the presacral space. Transperineal drainage has been shown to reduce pelvic infection in a series of combat wounds. ${ }^{53}$ As is often the case with the other components of traditional management, drain use has been questioned. Several retrospective studies have compared patients who underwent fecal diversion both with and without presacral drainage and showed no differences. ${ }^{54-56}$ The retrospective nature of these studies makes it difficult to determine the exact role of drainage in the prevention of infectious complications. The use of presacral drains has been evaluated in a prospective randomized trial of 48 patients. Although all were managed with diversion, infectious complications occurred in only one $(4 \%)$ of the 25 patients managed without a drain versus two $(8 \%)$ of the 23 patients with a drain. The authors concluded that presacral drainage has no role in the reduction of infectious complications. ${ }^{57}$ While it is difficult to make sweeping recommendations based on the available data, the use of presacral drainage should likely be limited, and when used, surgeons must ensure that drains communicate with the injury.

\section{Use of Distal Rectal Washout}

The theory behind the benefit of distal rectal washout centers on the potential for a persistent septic source in the pelvis. The possibility of continued fecal contamination via an open rectal wound can potentially be diminished by emptying the defunctionalized rectum. Those that advocate for this technique cite data that shows a decrease in septic complications in patients who had a washout performed. ${ }^{58}$ This position is further supported by the fact that nearly all of these patients underwent drainage of the presacral space, yet the benefit of 
a distal washout was still evident. Opponents of the technique claim that the presence of feces in the rectal vault bears no influence on the rate of sepsis, but state that the process of flushing liquid into the rectum may force stool and bacteria into tissue planes that would have otherwise been minimally contaminated. Since the 1990s, most series have demonstrated no significant advantage to distal washout in civilian rectal trauma. ${ }^{46,51,59}$ Although there has been limited prospective data addressing this issue, it appears that distal washout has no significant protective effect on the prevention infectious complications.

\section{Risks/Controversies}

\section{Risk Factors for Anastomotic Leak}

Anastomotic leak rates following primary repair of colonic and intraperitoneal rectal injuries in civilian trauma centers range from 0 to $15 \%,{ }^{5,38,60-62}$ with a large retrospective review demonstrating a leak rate of $2.4 \% .{ }^{63}$ Military series reveal slightly higher leak rates of $13-30 \%$. ${ }^{1,3,52,64-66}$ Multiple risk factors have been associated with the development of anastomotic leaks following primary repair, including severe fecal contamination, shock, excessive blood loss, multiple transfusions, concomitant intraabdominal organ injuries, and delayed presentation/surgery. ${ }^{21,67}$ In addition, the degree of colon injury (destructive versus nondestructive) has been identified as a potential indication for diversion due to a higher risk for anastomotic failure. ${ }^{5} \mathrm{~A}$ multicenter trial including only destructive wounds, demonstrated no difference in leak rate between the two methods of repair. ${ }^{35}$ Of the other major risk factors listed, only shock has consistently been associated with increased overall infectious complications, with prolonged hypotension being a predictor of mortality as well. ${ }^{41}$ The technique of anastomosis has also been evaluated to determine its impact on leak rates. A prospective nonrandomized trial found no difference in anastomotic leak rate (6.3 vs. $7.8 \%, P=0.69)$ between stapled versus handsewn techniques. ${ }^{68}$ Although some variables have been associated with both infectious and non-infectious complications, no single risk factor has consistently been demonstrated to be specific for anastomotic leak following primary repair, especially with nondestructive wounds or in a randomized trial.

\section{Right Versus Left Colon}

Despite what a survey of experienced trauma surgeons would suggest, ${ }^{69}$ there remains the perception that right- and leftsided colonic injuries may require different treatment. ${ }^{70,71}$ This persists despite data to suggest these injuries can be managed similarly. ${ }^{72}$ A 2002 study specifically evaluated patients with destructive colonic injuries, which they defined by need for resection, and found increased use of diversion with a left versus right colon injury ( 38 vs. $18.5 \%){ }^{22}$ Others have found comparable use of primary repair in right-sided versus left-sided colon injuries ( 55 vs. $48 \% ; P=0.52$ ). ${ }^{73}$ In a recent review of combat injuries, there was a definite trend in rates of diversion with left colon versus right colon injuries ( 36 vs. $19 \%, P=0.07$ ). ${ }^{3}$ Drawing conclusions from this data is again limited by flaws inherent to these studies. Possible explanations for these trends include surgeons' fears of inferior outcomes associated with primary repair in the face of higher injury severity, higher bacterial soilage with left-sided injuries, significant resuscitation requirements, or more severe associated injuries. The observed outcomes may simply reflect sound surgical judgment and application of appropriate management given the nature of injury and patient stability.

\section{Damage Control Surgery}

In order to avoid or interrupt the lethal triad of hypothermia, coagulopathy, and acidosis, the strategy of an abbreviated laparotomy may be employed. After controlling hemorrhage and contamination, the patient can be warmed, resuscitated, and stabilized in the ICU prior to proceeding with the definitive surgical procedure. There is debate over whether an anastomosis can be completed once the patient is stable. While some have shown comparable rates of infectious complications in those undergoing anastomosis, ${ }^{74,75}$ others have shown improved outcomes in those treated with a colostomy. ${ }^{76} \mathrm{An}$ analysis of primary repair in the damage control setting concluded that it is safe, despite results demonstrating higher leak rates than those patients undergoing a standard trauma laparotomy (16 vs. $0.3 \%))^{77,78}$ There is certainly a paucity of literature to guide decision making in this scenario. Controversy continues to exist surrounding the decision for timing of re-intervention and anastomosis or diversion after a damage control procedure. In most publications, the anastomosis occurred within $12-36 \mathrm{~h}$ after the initial procedure. Patients not anastomosed by the 36 -h mark may be best managed with a stoma, but we lack data to guide this decision.

\section{Conclusions and Recommendations}

In summary, colorectal injuries remain a challenge associated with significant morbidity. Surgeons must be familiar with a variety of treatment options as well as risk factors for complications. The use of proximal fecal diversion must be balanced by the complications associated with the presence of a stoma and its later takedown. The available data supports the notion that almost all civilian and military colon injuries can be repaired primarily with a low anastomotic leak rate that appears to be independent of the method of repair. We must, however, temper our enthusiasm for this data, as most of it is of lower 
quality. Intraperitoneal rectal injuries should be treated like injuries to the colon. Extraperitoneal rectal injuries, while still most often managed by proximal diversion, have also been successfully managed with selective proximal diversion, drainage and washout — especially those in the upper extraperitoneal rectum. Distal washout and presacral drainage should likely only be employed in select circumstances. Finally, overriding everything is the fact that sound surgical judgment remains priceless in the management of these patients. ${ }^{79}$

\section{References}

1. Hudolin T, Hudolin I. The role of primary repair for colonic injuries in wartime. Br J Surg 2005; 92: 643-7.

2. Uravic M. Colorectal war injuries. Mil Med 2000; 165: 186-8.

3. Steele SR, Wolcott KE, Mullenix PS, et al. Colon and rectal injuries during Operation Iraqi Freedom: are there any changing trends in management or outcome? Dis Colon Rectum 2007; 40: 870-7.

4. Cho SD, Kiraly LN, Flaherty SF, et al. Management of colonic injuries in the combat theater. Dis Colon Rectum 2010; 53: 728-34.

5. Williams MD, Watts D, Fakhry S. Colon injury after blunt abdominal trauma: results of the EAST Multi-Institutional Hollow Viscus Injury Study. J Trauma 2003; 55: 906-12.

6. Carillo EH, Somberg LB, Ceballos CE, Martini MA Jr, Ginzburg E, Sosa JL, Martin LC. Blunt traumatic injuries to the colon and rectum. J Am Coll Surg 1995; 183: 548-52.

7. Ng AK, Simons RK, Torreggiani WC, Ho SG, Kirkpatrick AW, Brown DR. Intraabdominal free fluid without solid organ injury in blunt abdominal trauma: an indication for laparotomy. J Trauma 2002; 52: 1134-1140.

8. Govender M, Madiba TE. Current management of large bowel injuries and factors influencing outcome. Injury 2010; 41:58-63.

9. Talton DS, Craig MH, Hauser CJ, Poole GV. Major gastroenteric injuries from blunt trauma. Am Surg 1995; 61: 69-73.

10. Mangiante EC, Graham AD, Fabian TC. Rectal gunshot wounds. Management of civilian injuries. Am Surg 1986; 52: 37-40.

11. Shlamovitz GZ, Mower WR, Bergman J, et al. Poor test characteristics for the digital rectal examination in trauma patients. Ann Emerg Med 2007; 50: 25-33.

12. Porter JM, Ursic CM. Digital rectal examination for trauma: does every patient need one? Am Surg 2001; 67: 438-41.

13. Esposito TJ, Ingraham A, Luchette FA. Reasons to omit digital rectal exam in trauma patients: no fingers, no rectum, no useful additional information. J Trauma 2005; 59: 1341-9.

14. Udobi KF, Rodriguez A, Chiu WC, Scalea TM. Role of ultrasonography in penetrating abdominal trauma: a prospective clinical study. J Trauma 2001; 50: 475-9.

15. Shanmuganathan K, Mirvis SE, Chiu WC, Killeen KL, Scalea TM. Triple-contrast helical CT in penetrating torso trauma: a prospective study to determine peritoneal violation and the need for laparotomy. AJR Am J Roentgenol 2001; 177: 1247-56.

16. Shanmuganathan K, Mirvis SE, Chiu WC, Killeen KL, Hogan GJ, Scalea TM. Penetrating torso trauma: triple-contrast helical CT in peritoneal violation and organ injury-a prospective study in 200 patients. Radiology 2004; 231:775-84.

17. Otomo Y, Henmi H, Mashiko K, et al. New diagnostic peritoneal lavage criteria for diagnosis of intestinal injury. J Trauma 1998; 44: 991-7.

18. Henneman PL, Marx JA, Moore EE, Cantrill SV, Ammons LA. Diagnostic peritoneal lavage: accuracy in predicting necessary laparotomy following blunt and penetrating trauma. J Trauma 1990; 30: 1345-55.

19. Renz BM, Feliciano DV. Unnecessary laparotomies for trauma: a prospective study of morbidity. J Trauma 1995; 38: 350-6.

20. Woodhall J, Ochsner A. The management of perforating injuries of the colon and rectum in civilian practice. Surgery 1951;29: 305-20.

21. Stone H, Fabian T. Management of perforating colon trauma: randomization between closure and exteriorization. Ann Surg 1979; 190: 430-6.

22. Miller P, Fabian T, Croce M, et al. Improving outcomes following penetrating colon wounds: application of a clinical pathway. Ann Surg 2002; 235: 775-81.

23. Abcarian H. Rectal trauma. Gastroenterol Clin North Am 1987; 16 : 115-23.

24. Baako BN. Colostomy: its place in the management of colorectal injuries in civilian practice. West Afr J Med 1998; 17: 109-12.

25. Morris D, Sugrue W. Abdominal injuries in the war wounded of Afghanistan: a report from the International Committee of the Red Cross Hospital in Kabul. Br J Surg 1991; 78: 1301-4.

26. Chappuis CW, Frey DJ, Dietzen CD, Panetta TP, Buechter KJ, Cohn I Jr. Management of penetrating colon injuries. A prospective randomized trial. Ann Surg 1991; 213: 492-7.

27. Jacobsen LE, Gomez GA, Broadie TA. Primary repair of 58 consecutive penetrating injuries of the colon: should colostomy be abandoned? Am Surg 1997; 63: 170-7.

28. Sasaki LS, Allaben RD, Golwala R, Mittal VK. Primary repair of colon injuries: a prospective randomized study. J Trauma 1995; 39: 895-901.

29. Berne JD, Velhamos GC, Chan LS, Asensio JA, Demetriades D. The high morbidity of colostomy closure after trauma: further support for the primary repair of colon injuries. Surgery 1998; 123: 157-64.

30. Gonzalez RP, Merlotti GJ, Holevar MR. Colostomy in penetrating colon injury: is it necessary? J Trauma 1996; 41: 271-5.

31. Durham RM, Pruitt C, Moran J, Longo WE. Civilian colon trauma: factors that predict success by primary repair. Dis Colon Rectum 1997; 40: 685-92.

32. Miller BJ, Schache DJ. Colorectal injury: where do we stand with repair? Aust N Z J Surg 1996; 66: 348-52.

33. Pasquale M, Fabian TC. Practice management guidelines for trauma from the Eastern Association for the Surgery of Trauma. J Trauma 1998; 44: 941-56.

34. Mickevicius A, Klizaite J, Tamelis A, et al. Penetrating colorectal trauma: index of severity and results of treatment. Medicina (Kaunas) 2003; 39: 562-9.

35. Demetriades D, Murray JA, Chan L, et al. Penetrating colon injuries requiring resection: diversion or primary anastomosis? An AAST prospective multicenter trial. J Trauma 2001; 50: 765-75.

36. Singer MA, Nelson RL. Primary repair of penetrating colon injuries: a systematic review. Dis Colon Rectum 2002; 45: 1579-87.

37. Nelson R, Singer M. Primary repair for penetrating colon injuries. Cochrane Database Syst Rev. 2003;(3): CD002247.

38. Stewart RM, Fabian TC, Croce MA, et al. Is resection with primary anastomosis following destructive colon wounds always safe? Am J Surg 1994; 168: 316-19.

39. DuBose J. Colonic trauma: indications for diversion vs. repair. J Gastrointest Surg 2009; 13: 403-4.

40. Halvorsen JF, Vagn Nielson O, Bugge-Asperheim B. Injuries of the colon and rectum. Ann Chir Gynaecol 1981; 70: 787-91.

41. Cleary RK, Pomerantz RA, Lampman RM. Colon and rectal injuries. Dis Colon Rectum 2006; 49: 1203-1222.

42. Lavenson GS, Cohen A. Management of rectal injuries. Am J Surg 1971; 122: 226-30.

43. Wiedeman JE, Rignault DP. Civilian versus military trauma dogma: who do you trust? Mil Med 1999; 164: 256-60. 
44. Herr MW, Gagliano RA. Historical perspective and current management of colonic and intraperitoneal rectal trauma. Curr Surg 2005; 6: 187-92.

45. Burch JM, Feliciano DV, Mattox KL. Colostomy and drainage for civilian rectal injuries: is that all? Ann Surg 1989; 209: 600-11.

46. Bostick PJ, Johnson DA, Heard JF, et al. Management of extraperitoneal rectal injuries. J Natl Med Assoc 1993; 85: 460-3.

47. Haas PA, Fox TA Jr. Civilian injuries of the rectum and anus. Dis Colon Rectum 1977; 2: 17-23.

48. Gonzalez RP, Phelan H 3rd, Hassan M, Ellis CN, Rodning CB. Is fecal diversion necessary for nondestructive penetrating extraperitoneal rectal injuries? J Trauma 2006; 61: 815-9.

49. Velmahos GC, Gomez H, Falabella A, Demetriades D. Operative management of civilian rectal gunshot wounds: simpler is better. World J Surg 2000; 24: 114-8.

50. Levine JH, Longo WE, Pruitt C, et al. Management of selected rectal injuries by primary repair. Am J Surg 1996; 172: 575-8.

51. McGrath V, Fabian TC, Croce MA, Minard G, Pritchard FE. Rectal trauma: management based on anatomical distinctions. Am Surg1998; 64: 1136-41.

52. Duncan JE, Corwin CH, Sweeney, WB, et al. Management of colorectal injuries during operation Iraqi freedom: patterns of stoma usage. J Trauma 2008; 64: 1043-7.

53. Armstrong RG, Schmitt HJ Jr., Patterson LT. Combat wounds of the extraperitoneal rectum. Surg 1973; 74: 570-83.

54. Levy RD, Strauss P, Aladgem D, Degiannis E, Boffard KD, Saadia R. Extraperitoneal rectal gunshot injuries. J Trauma 1995; 38: $273-7$.

55. Navsaria PH, Edu S, Nicol AJ. Civilian extraperitoneal rectal gunshot wounds: surgical management made simpler. World J Surg 2007; 31: 1345-51.

56. Steinig JP, Boyd CR. Presacral drainage in penetrating extraperitoneal rectal injuries: is it necessary? Am Surg 1996; 62: 765-7.

57. Gonzalez RP, Falimirski ME, Holevar MR. The role of presacral drainage in the management of penetrating rectal injuries. J Trauma 1998; 45: 656-61.

58. Shannon FL, Moore EE, Moore FA, McCroskey BL. Value of distal colon washout in civilian rectal trauma-reducing gut bacterial translocation. J Trauma 1988; 28: 989-94.

59. Ivatury RR, Licata J, Gunduz Y, Rao P, Stahl WM. Management options in penetrating rectal injuries. Am Surg 1991; 57: 50-5.

60. Kamwendo NY, Modiba M, Matlala N, Becker PJ. Randomized clinical trial to determine if delay from time of penetrating colonic injury precludes primary repair. Br J Surg 2002; 89: 993-98.

61. Slim MS, Makaroun M, Shamma AR. Primary repair of colorectal injuries in childhood. J Pediatr Surg 1981; 16: 1008-11.

62. Maxwell RA, Fabian TC. Current management of colon trauma. World J Surg 2003; 27: 632-9.

63. Curran TJ, Borzotta AP. Complications of primary repair of colon injury: literature review of 2,964 cases. Am J Surg 1999; 177: $42-47$.

64. Vertrees A, Wakefield M, Pickett C, et al. Outcomes of primary repair and primary anastomosis in war-related colon injuries. $\mathrm{J}$ Trauma 2009; 66: 1286-91.

65. Payravi H, Mortza SS, Fazel I. Surgical treatment results of Iranian abdominal trauma casualties in the Iran and Iraq war. Mil Med 2001; 166: 952-4.

66. Saghafinia M, Nafissi N, Motamedi MR, et al. Assessment and outcome of 496 penetrating gastrointestinal warfare injuries. J R Army Med Corps 2010; 156: 25-7.

67. Stankovic N, Petrovic M, Drinkovic N, Bjelovic M, Jevtic M, Mirkovic D. Colon and rectal war injuries. J Trauma 1996; 40(Suppl): S183-8.

68. Demetriades D, Murray JA, Chan LS, et al. Handsewn versus stapled anastomosis in penetrating colon injuries requiring resection: a multicenter study. J Trauma 2002; 52: 117-21.

69. Eshraghi N, Mulins RJ, Mayberry JC, Brand DM, Crass RA, Trunkey DD. Surveyed opinion of American trauma surgeons in the management of colon injuries. J Trauma 1998; 44: 93-7.
70. Adesanya AA, Ekanem EE. A ten-year study of penetrating injuries of the colon. Dis Colon Rectum 2004; 47: 2169-77.

71. Murray J, Demetriades D, Colson M, et al. Colonic resection in trauma: colostomy versus anastomosis. J Trauma 1999; 46: $250-4$.

72. Thompson JS, Moore EE, Moore JB. Comparison of penetrating injuries of the right and left colon. Ann Surg 1981; 193: 414-18.

73. Fealk M, Osipov R, Foster K, Caruso D, Kassir A. The conundrum of traumatic colon injury. Am J Surg 2004; 188: 663-70.

74. Miller PR, Chang MC, Hoth JJ, Holmes JH 4th, Meredith JW. Colonic resection in the setting of damage control laparotomy: is delayed anastamosis safe? Am Surg 2007; 73: 606-9.

75. Ordonez CA, Pino LF, Badiel M, et al. Safety of performing a delayed anastomosis during damage control laparotomy in patients with destructive colon injuries. J Trauma 2011; 71: 1512-18.

76. Weinberg JA, Griffin RL, Vandromme MJ, et al. Management of colon wounds in the setting of damage control laparotomy: a cautionary tale. J Trauma 2009; 67: 929-35.

77. Kashuk JL, Cothren CC, Moore EE, et al. Primary repair of civilian colon injuries is safe in the damage control scenario. Surgery 2009; 146: $663-8$.

78. Burlew CC, Moore EE, Cuschieri J, et al. Sew it up! A Western Trauma Association multi-institutional study of enteric injury management in the postinjury open abdomen. J Trauma 2011; 70: $273-7$.

79. Steele SR, Maykel J A, Johnson EK. Traumatic injury of the colon and rectum: the evidence vs dogma. Dis Colon Rectum 2011; 54: $1184-1201$.

\section{MOC Questions: Colorectal Trauma}

1. A 50-year-old male presents with a single, low-velocity gunshot to the abdomen. During laparotomy, he is found to have a destructive wound to the cecum with moderate fecal contamination of the peritoneal cavity. Blood pressure is $100 / 70$ and heart rate is 100 . The best method of management would be:

a. Primary repair of the injury

b. Ileocecectomy with primary anastomosis

c. Right colectomy with end ileostomy and mucous fistula

d. Damage control right colectomy

2. Which of the following is the best treatment of a destructive extraperitoneal rectal injury?

a. Direct repair of the injury

b. Distal rectal washout

c. Presacral drainage

d. Diverting colostomy

3. A 22-year-old male is stabbed in the lower abdomen during a fight. On exam, the wound clearly penetrates the fascia. During laparotomy, he is found to have an intraperitoneal bladder injury and an injury to the anterior wall of the intraperitoneal rectum. The best management would be:
a. Primary repair of the injuries
b. Anterior resection and anastomosis
c. Diverting loop colostomy
d. Hartmann's resection

4. A 65-year-old male with coronary disease suffers a blunt left colon injury during a motor vehicle collision. He is hypotensive on presentation and receives six units of blood products. In the OR, he is found to have a 
destructive left colon injury with a large hemoperitoneum and severe fecal contamination. The best management would be:

a. Exteriorization of the injury

b. Hartmann's resection

c. Left colectomy with primary anastomosis

d. Primary repair of the injury

5. If presacral drains are employed in the management of penetrating rectal trauma, which of the following is essential?

a. Drains must be irrigated daily

b. Drains must be placed adjacent to the injury

c. A distal rectal washout must be performed

d. The injury should be repaired primarily

6. A patient undergoes a damage control laparotomy after sustaining an abdominal gunshot wound. During the first procedure, a splenectomy, left nephrectomy, and two segmental small bowel resections were performed without anastomosis. Once stable, the patient is taken back to the OR and a small laceration to the mid descending colon is noted with minimal contamination. The best management of this injury is:

a. Primary repair

b. Segmental resection and anastomosis

c. Hartmann's resection

d. Segmental resection, anastomosis, diverting loop ileostomy

7. A 30-year-old blunt trauma patient is found to have a destructive injury of the right mesocolon resulting in significant hemorrhage. High ligation of the ileocolic artery as well as several ligations of the marginal artery in the right colonic mesentery is required to control the bleeding. The patient is stable. The right colon is undamaged, but appears bruised in several areas. The best management would be:

a. Control bleeding and close

b. Perform right colectomy with primary anastomosis

c. Perform right colectomy with end ileostomy

d. Perform right colectomy with end ileostomy and mucous fistula

8. A patient presents to the emergency department after being injured by an improvised explosive device. He complains of abdominal pain and is noted to have several fragmentation wounds of the anterior abdominal wall. Exam reveals intralumenal blood on rectal exam. The next step should be:

a. Serial abdominal exams

b. Rigid proctoscopy examination of the rectum

c. Retrograde urethrogram

d. CT cystogram

Answers:

1. b

2. d

3. a

4. $b$

5. b

6. a

7. b

8. b 